\title{
Monitoring and Analysis of Power Quality in Photovoltaic Power Generation System
}

\author{
JI Cui ${ }^{1}$, HUA Siming ${ }^{1}$, ZOU Bingbing ${ }^{1}$, ZHANG Hua ${ }^{1}$, DIAO Chang ${ }^{1}$, ZHOU Guofa ${ }^{2}$, MIN Bo ${ }^{2}$ \\ ${ }^{1}$ State Grid Shanghai Fengxian Electric Power Company, Shanghai Fengxian 201499, China. \\ ${ }^{2}$ Shanghai Puhai Qiushi Electric Power High Technology Co.,Ltd., Shanghai 200090, China.
}

\begin{abstract}
Solar photovoltaic (PV) has been developed rapidly due to its clean and green renewable characteristics. The connection of photovoltaic power generation to the traditional grid system is bound to bring power quality problems. Based on above, this paper introduces the power quality testing method of photovoltaic grid-connected power grid in detail. And then takes the Shanghai Qingpu Nanrong distributed photovoltaic power generation for example, which is the largest single roof photovoltaic power station in Shanghai by far, to use the method to test its power quality. The power quality index include harmonic, voltage imbalance, and frequency deviation. The test and analysis provide a reference for the monitoring and analysis of power quality of photovoltaic grid-connected power grid.
\end{abstract}

\section{Introduction}

At present, China is still based on thermal power generation. Although the proportion of nuclear power, wind power and solar power is improved, the capacity of thermal power installed capacity still accounts for most of the total installed capacity of electric power, and the proportion of thermal power generation accounts for more than $80 \%$ of the total power generation [1]. When generating electricity, a large amount of coal needs to be burned, which not only demands for large coal resources, but also causes destruction to the environment. Despite of the decreasing of the coal when thermal power generating electricity [1], the environmental pressure brought by it is still not small. Under the pressure of energy depletion and environmental pollution, people have to turn their attention to clean and renewable new energy sources [2]. Solar photovoltaic power generation is inexhaustible and clean and environmentally friendly, so it has attracted wide attention [3-7].Under the influence of sustainable development and national energy strategy layout, more and more new distributed energy sources have been applied to modern power grid, and even many countries have the tendency to replace the conventional energy with distributed energy. Solar energy is the most abundant resource on the earth. The annual radiation from the sun to the earth's surface reaches to $5.4 * 1024 \mathrm{~J}$, equivalent to $1.8 * 1014 \mathrm{t}$ standard coal. If only $0.1 \%$ of the energy is converted to electricity by $5 \%$ conversion rate, the annual generating capacity can reach to $5600 \mathrm{TWh}$, equivalent to 40 times the current world energy consumption. If we can make rational use of solar energy, we will greatly alleviate the resource pressure facing the world at present [3].

The principle of solar photovoltaic power generation is the photoelectric effect. Photoelectric effect refers to the semiconductor material in the solar energy under the action of light, its internal electronic directional movement and form an electric current. The formation of a large scale photovoltaic array is to encapsulate a single photovoltaic cell and then connect a wire to a circuit according to the need to meet the requirements of a larger DC power output.

Photovoltaic power generation uses clean energy solar energy to generate electricity, which does not consume fuel and has no pollution to the environment. Its installation is not restricted by the region and can be flexible to set up its installation capacity as needed. At the same time, photovoltaic power plant operation is safe and reliable, and later maintenance is relatively simple [3].

However, after solar PV grid connected, the fluctuation of PV will lead to the power quality problems, such as voltage fluctuation, voltage flicker, frequency fluctuation and so on. At the same time, the photovoltaic inverter components will lead to the power quality problems such as harmonic and DC component [4,8]. Therefore, the grid connected photovoltaic has to consider the power quality problems brought by it.

Based on the above, this paper will introduce the method of measuring the power quality of photovoltaic grid connected power, and test the power quality of the power station with the largest single roof photovoltaic power station in Shanghai, Shanghai City, Qingpu District, and carry out the power quality test of the power station, and carry out the harmonic, voltage imbalance, 
frequency deviation and other electrical energy for the test results. The quality index analysis provides a reference for monitoring and analyzing the power quality of grid connected PV system.

\section{Power quality testing process}

\section{1 test tool}

This test adopts the PW3198 power quality analyzer of Japan electric motor Co., Ltd.

\section{2 test environment}

Because of the sensitivity of photovoltaic components and photovoltaic inverters to environmental conditions, the environmental conditions of the test have a great influence on the test results. So the test should have appropriate environmental conditions. Under normal circumstances, the recommended test environment temperature is $-10 \sim 50$ degrees $\mathrm{C}$, the ambient humidity is not more than $90 \%$.

\subsection{Test location}

Test location: PV power station network terminal and point of common coupling (PCC). As shown in Figure 1.

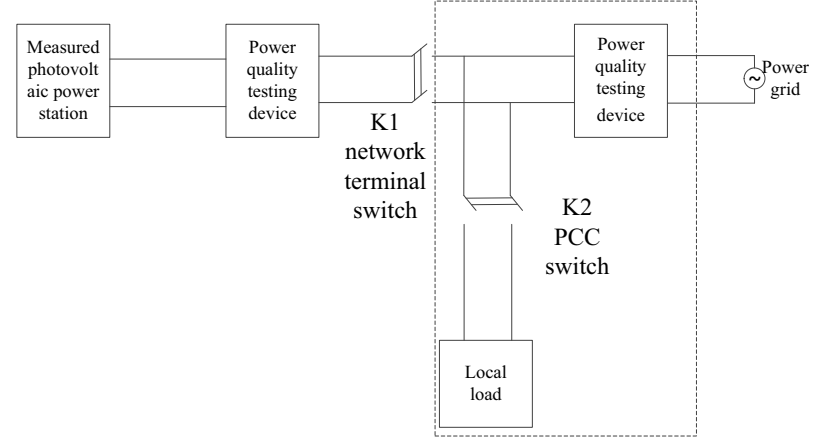

Fig.1 Power quality test schematic diagram

\section{4 test procedure}

1) The power quality test points should be located in PV power stations and outlets and public connection points.

2) Check the capacity of the photovoltaic power station actually put into the power grid.

3) The electric energy quality test device is used to measure the parameters of the energy quality index of the test point. Under the normal operation of the system, the continuous measurement is at least one day (with a complete irradiation period).

4) Read the test data of power quality test equipment and analyze it to determine whether to meet the relevant requirements.

\subsection{Theoretical calculation of power quality}

1) Harmonic
The main theoretical calculation formulas for harmonics are shown as follows [9].

$$
H R U_{\mathrm{h}}=\frac{U_{\mathrm{h}}}{U_{1}} \times 100 \%
$$

Harmonic voltage content of $\mathrm{h}^{\text {th. }}$ :

$$
U_{H}=\sqrt{\sum_{h=2}^{\infty}\left(U_{\mathrm{h}}\right)^{2}}
$$

Total voltage harmonic distortion rate:

$$
T H D_{\mathrm{u}}=\frac{U_{\mathrm{H}}}{U_{1}} \times 100 \%
$$

2) Voltage imbalance

The severity of voltage imbalance is often quantified by (negative sequence) voltage unbalance. It is defined as the ratio of negative sequence voltage $U_{-1}$ to positive sequence voltage $U_{+1}$. It is generally expressed as a percentage [5]:

$$
K_{\mathrm{d}}=\frac{U_{-1}}{U_{+1}} \times 100 \%
$$

Sometimes, the regional distribution company uses the difference between the maximum and minimum of the steady phase voltage or line voltage to quantify the unbalanced voltage.

\section{General situation of photovoltaic power station}

The capacity of the PV module is $5983 \mathrm{kWp}$. The annual $\mathrm{PV}$ power generation is $3647640 \mathrm{kWh}$, and the maximum user demand is $309080 \mathrm{kWh}$. The grid type is first to meet self-need and the surplus electricity supplies to the grid. According to the regulations and site conditions of Typical design of distributed photovoltaic power generation access system in State Grid, this project is divided into 6 connection points, and the capacity of the PV module are 4 groups of $1247.75 \mathrm{kWp}$ and 2 groups of $496 \mathrm{kWp}$ respectively. The PV module is partially connected to the low voltage distribution cabinet of the low-voltage side bus of the user distribution station, and some of the power stations are connected to the user distribution station. High voltage power distribution cabinet with high voltage side bus.

The wiring diagram of the photovoltaic power station is shown in Figure 2.



Fig. 2 Electrical diagram of photovoltaic station 


\section{Test and analysis}

This article mainly carries on the power quality test to the high voltage side and the low voltage side of \#1-\#6 transformer in Qingpu NGO distributed photovoltaic power station.

\section{1 harmonic analysis}

The harmonic content of the photovoltaic power station should be controlled in the range of the allowable value stipulated in the GB14549-1993 power quality public power grid harmonics. The total harmonic distortion rate of the $10 \mathrm{kV}$ bus voltage is not more than $4 \%$. The odd harmonic content is not more than $3.2 \%$, and the ratio of the even subharmonics is not more than $1.6 \%$. Otherwise, the corresponding filter device should be equipped to avoid harmonic pollution to the public power grid.The harmonic test result of the high voltage side and low voltage side of each transformer in Qingpu photovoltaic power station are shown in Table 1. It can be seen from table 1 that the voltage values of each harmonic are small and all within the limit specified by the state. Fig. 3 to Fig. 6 show the voltage waveforms of the $2 \#$ and $4 \#$ transformers on the high voltage side and the AC side of the inverter and the corresponding harmonic voltage fraction. As shown in Fig. 3 to Fig. 6 that the voltage waveform is smooth, and the harmonic voltage fraction is low, and there is no abnormal condition.

Tab.1 Harmonic result

\begin{tabular}{cccccc}
\hline \multirow{2}{*}{$\begin{array}{c}\text { Transformer } \\
\text { name }\end{array}$} & $\begin{array}{c}\text { Rated } \\
\text { capacity } \\
(\mathrm{kVA})\end{array}$ & $\begin{array}{c}\text { High voltage side } \\
\text { THD }(\%)\end{array}$ & HRU(\%) & THD $(\%)$ & HRU $(\%)$ \\
\hline $1 \#$ & 630 & 2.39 & 2.23 & 2.26 & 1.99 \\
$2 \#$ & 630 & 1.51 & 1.42 & 1.64 & 1.43 \\
$3 \#$ & 1250 & 2.50 & 2.38 & 2.15 & 1.89 \\
$4 \#$ & 1250 & 1.45 & 1.34 & 1.84 & 1.65 \\
$5 \#$ & 1250 & 2.30 & 2.10 & 2.15 & 1.89 \\
$6 \#$ & 1250 & 1.47 & 1.38 & 1.70 & 1.54 \\
\hline
\end{tabular}

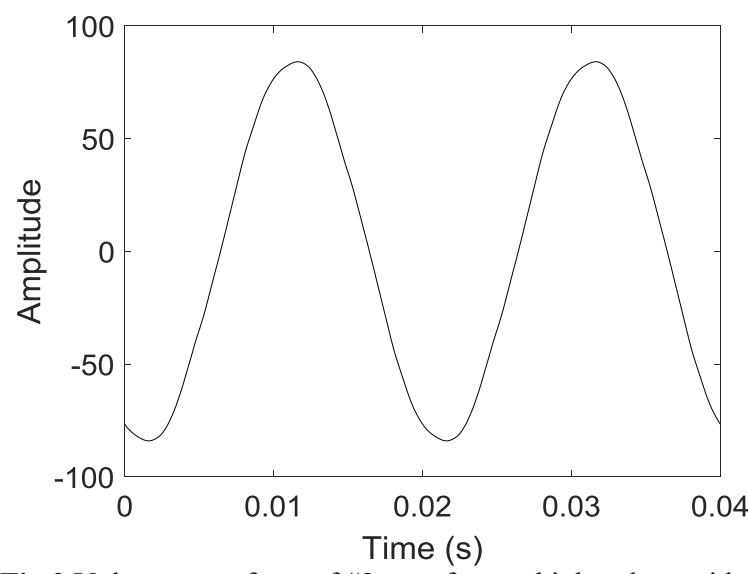

Fig.3 Voltage waveform of \#2 transformer high voltage side

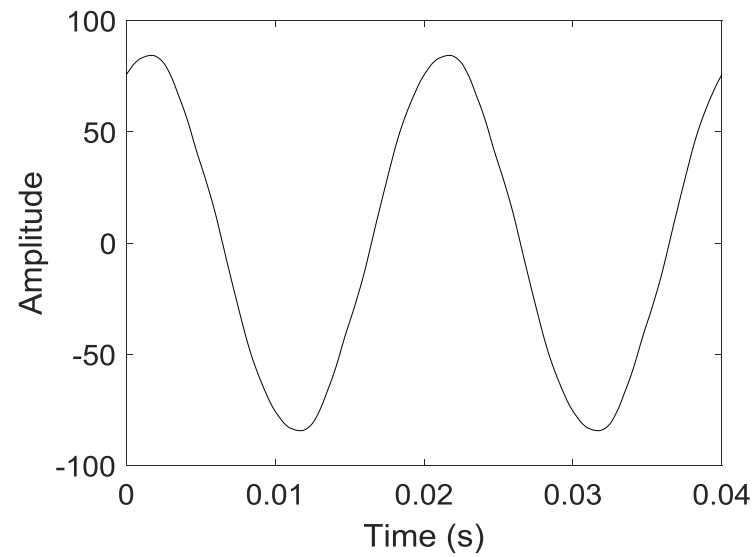

Fig.4 Voltage waveform of \#4 transformer high voltage side

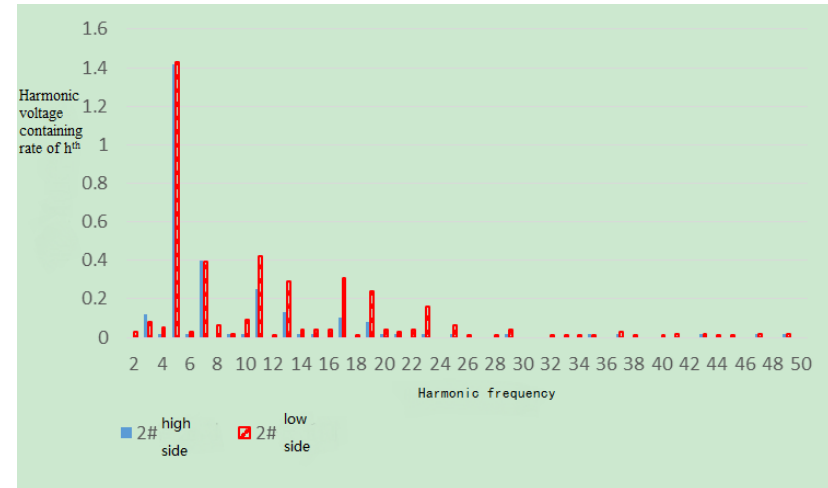

Fig.5 HRU of \#2 transformer high voltage side and low voltage side

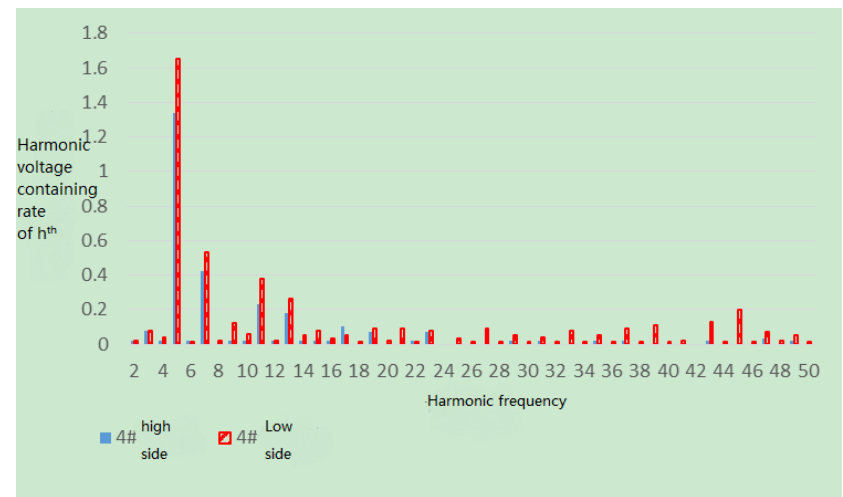

Fig.6 HRU of \#2 transformer high voltage side and low voltage side

\subsection{Analysis of voltage imbalance}

When the PV power station is connected to the power grid, the voltage imbalance of the PCC should not exceed the requirements of $G B / T$ 15543-2008 power quality three-phase voltage imbalance.

The negative sequence voltage unbalance test values of high voltage side and low voltage side of each transformer in Qingpu NGO photovoltaic power station are shown in Table 2. As shown in Table 2, the PV power station satisfies the requirement that the negative sequence voltage imbalance of the common connection point is less than $2 \%$. 
Tab.2 Voltage imbalance result

\begin{tabular}{cccc}
\hline $\begin{array}{c}\text { Transformer } \\
\text { name }\end{array}$ & $\begin{array}{c}\text { Rated capacity } \\
(\mathrm{kVA})\end{array}$ & $\begin{array}{c}\text { Voltage imbalance (\%) } \\
\text { High voltage } \\
\text { side }\end{array}$ & $\begin{array}{c}\text { Low voltage } \\
\text { side }\end{array}$ \\
\hline $1 \#$ & 630 & 0.2 & 0.28 \\
$2 \#$ & 630 & 0.2 & 0.16 \\
$3 \#$ & 1250 & 0.21 & 0.22 \\
$4 \#$ & 1250 & 0.17 & 0.11 \\
$5 \#$ & 1250 & 0.29 & 0.28 \\
$6 \#$ & 1250 & 0.14 & 0.17 \\
\hline
\end{tabular}

\section{Frequency deviation}

After the PV power station is connected to the power grid, the frequency deviation of the PCC should not exceed the requirement of GB/T 15943-2008 power quality power system frequency deviation. The frequency deviation test values of high voltage side and low voltage side of each transformer in Qingpu NGO photovoltaic power station are shown in Table 3. It can be seen from table 3 that the PV power station satisfies the requirement of frequency deviation of the PCC less than $\pm 0.2 \mathrm{~Hz}$.

Tab.3 Frequency deviation result

\begin{tabular}{|c|c|c|c|c|}
\hline $\begin{array}{l}\text { Transforme } \\
\text { r name }\end{array}$ & $\begin{array}{l}\text { High } \\
\text { voltage } \\
\text { side } \\
\text { frequency } \\
\quad(\mathrm{Hz})\end{array}$ & $\begin{array}{c}\text { High } \\
\text { voltage } \\
\text { side } \\
\text { frequency } \\
\text { deviation } \\
(\mathrm{Hz}) \\
\end{array}$ & $\begin{array}{l}\text { Low } \\
\text { voltage } \\
\text { side } \\
\text { frequency } \\
\quad(\mathrm{Hz})\end{array}$ & $\begin{array}{c}\text { Low } \\
\text { voltage } \\
\text { side } \\
\text { frequency } \\
\text { deviation } \\
(\mathrm{Hz}) \\
\end{array}$ \\
\hline $1 \#$ & 50.026 & 0.026 & 50.002 & 0.002 \\
\hline 2\# & 49.971 & 0.029 & 49.980 & 0.020 \\
\hline 3\# & 49.964 & 0.036 & 49.963 & 0.037 \\
\hline $4 \#$ & 49.964 & 0.036 & 50.009 & 0.009 \\
\hline $5 \#$ & 49.975 & 0.025 & 49.981 & 0.019 \\
\hline $6 \#$ & 49.976 & 0.024 & 49.997 & 0.003 \\
\hline
\end{tabular}

\section{Conclusion}

In this paper, by introducing the method of measuring the quality of grid connected photovoltaic power, and combining with the largest photovoltaic power station in Shanghai, the Qingpu District of Shanghai, the power quality test of the power station is carried out, and the test results are analyzed, such as harmonic, voltage imbalance, frequency deviation and so on. The results show that the PV system is running well, and its access has no adverse effect on the power quality of the grid. But in the actual operation process, we should also take more precaution. With the increasing capacity of photovoltaic access, the problem of power quality will become more and more prominent. It is very important to master the method of power quality testing. It is necessary to test the power quality of the grid system regularly, to find problems early and solve problems early, and to provide security for the safe and stable operation of the power grid.

\section{References}

1. YANG Yongping, YANG Zhiping, XU Gang, WANG Ningling.Situation and Prospect of Energy Consumption for China's Thermal Power Generation[J].Proceedings of the CSEE,2013,33(23):1-11.

2. DING Ming, WANG Weisheng, WANG Xiuli, SONG Yunting, CHEN Dezhi, SUN Ming.A Review on the Effect of Large-scale PV Generation on Power Systems[J].Proceedings of the CSEE ,2014,34(1):1-14.

3. CHEN Wei,AI Xin,WU Tao,LIU Hui.Influence of grid-connected photovoltaic system on power network[J].Electric Power Automation Equipment,2013,33(2):26-32.

4. SANG Jingjing.Study of Impacts of Grid-connected PV on Distribution System[D]. Taiyuan University of Technology,2010.

5. XU Qun. Effects and Assessment on Power Quality of Distribution network with Distributed Generation[D]. North China Electric Power University,2012.

6. LIU Wei, PENG Dong, BU Guangquan, SU Jian.A Survey on System Problems in Smart Distribution Network With Grid-Connected Photovoltaic Generation[J]. Power System Technology,2009,33(19):1-6.

7. Wang Wenjing, Wang Sicheng .Status and Prospect of Chinese Distributed Photovoltaic Power Generation System[J].Journal of the Chinese academy of sciences,2016,31(2):165-172.

8. Han Fujia, Wang Chun.Influences of the distributed photovoltaic grid-connected generation system on the distribution network power quality based on Matlab[J].Electrical Measurement \& Instrumentation,2015,52(15):16-21.

9. GB14549-93, Power quality common grid harmonics[S].State technical supervision bureau of the People's Republic of China, 1994. 